\title{
Pedicle frozen autograft-prosthesis composite reconstructions for malignant bone tumors of the proximal femur
}

\author{
Gang Xu, Shinji Miwa, Norio Yamamoto*, Katsuhiro Hayashi, Akihiko Takeuchi, Kentaro Igarashi, Takashi Higuchi, \\ Yuta Taniguchi, Yoshihiro Araki, Hirotaka Yonezawa, Sei Morinaga and Hiroyuki Tsuchiya
}

\begin{abstract}
Background: Limb salvage surgery is becoming increasingly popular after tumor resection in the lower extremity. Biological reconstruction and use of megaprosthesis are main methods for malignant bone tumors of the proximal femur, which remain controversial due to short- and long-term complication in the proximal femur. Tumor-bearing bone treated by liquid nitrogen is one of biological reconstruction. This study aimed to evaluate the mid- and longterm functional outcomes and complications in patients treated with frozen autograft-prosthesis composite (FAPC) reconstructions in the proximal femur.
\end{abstract}

Methods: This retrospective study included 19 patients ( 10 women, 9 men) with malignant tumors of the proximal femur who underwent tumor-wide resection and FAPC reconstruction (mean age, 46 years; range, 9-77 years). The mean follow-up period of 69 months (range, 9-179 months). Functional outcomes, oncological outcome and complications were evaluated by Musculoskeletal Tumor Society score, clinical and radiological examinations.

Results: The overall survival rate was 68.4\%, and the mean Musculoskeletal Tumor Society functional score was 26.4 points (88\%). FAPC survival rates were 100 and $50 \%$ at 5 and 10 years, respectively. Five of the 19 patients (26\%) had complications: 2 required prosthesis removal and 2 developed a deep infection around acetabular. Wear of the acetabulum occurred in 2 cases, while disease recurrence was occurred in 1 case. There were no cases of greater trochanter avulsion, obvious absorption around frozen bone, prosthesis loosening or leg length discrepancy.

Conclusions: Due to without femoral osteotomy, this technique features satisfactory functional outcome and provide biomechanical stability that is comparable to those of other methods of biological reconstruction or megaprosthesis.

Keywords: Frozen autograft-prosthesis composite, Proximal femur, Malignant bone tumors, Biological reconstruction, Tumor-bearing bone graft, Liquid nitrogen

\section{Introduction}

The proximal femur is a common site of malignant bone tumors, however, the options for reconstruction after tumor resection are limited due to the requirement of reconstruction of the hip-joint. In recent years, the quality of the patient's life has been remarkably improved largely attributed to the great advances in chemotherapy, radiotherapy, radiological examination and surgical techniques. The 5-year survival rate of non-metastatic osteosarcoma

\footnotetext{
* Correspondence: norinori@med.kanazawa-u.ac.jp

Department of Orthopaedic Surgery, Kanazawa University School of

Medicine, 13-1 Takara-machi, Kanazawa, Ishikawa 920-8641, Japan
}

has increased to close to $70 \%$, while the lower-extremity functional outcomes were $71-87 \%$ on the Musculoskeletal Tumor Society (MSTS) system [1, 2]. Importantly, no significant difference was reported in overall survival rate or functional outcome between amputation and limb-sparing surgery [3]. Therefore, limb salvage surgery is becoming increasingly popular after tumor resection in the lower extremity [2-4].

Megaprosthesis and allograft-prosthesis composite (APC) reconstructions are the most widely used in the proximal femur reconstruction $[4,5]$. Megaprosthesis and APC reportedly have various advantages in short- and

(c) The Author(s). 2020 Open Access This article is distributed under the terms of the Creative Commons Attribution 4.0 International License (http://creativecommons.org/licenses/by/4.0/), which permits unrestricted use, distribution, and reproduction in any medium, provided you give appropriate credit to the original author(s) and the source, provide a link to the Creative Commons license, and indicate if changes were made. The Creative Commons Public Domain Dedication waiver (http://creativecommons.org/publicdomain/zero/1.0/) applies to the data made available in this article, unless otherwise stated. 
long-term functional outcomes, respectively $[4,6,7]$. However, the biological and nonbiological reconstructions after malignant tumor resection remain controversial in the proximal femur. In principle, the ideal proximal femur reconstruction method includes local tumor control, optimal limb function stability, and restoration of the maximal hip abductor function. Since 1999, we developed a tumorbearing autograft using liquid nitrogen and reported its application for reconstruction in patients with malignant bone tumor [8]. Pedicle freezing is a method of creating a tumor-bearing autograft using liquid nitrogen [9].

In the current study, we focused on the radiological and functional outcomes for frozen autograft-prosthesis composite (FAPC) reconstruction by pedicle freezing in the proximal femur. We attempted to answer following questions: (1) investigate the mid- and long-term functional outcomes and complications in patients treated with FAPC reconstruction and (2) compare the functional outcomes and survival rates of various reconstruction methods.

\section{Materials and methods \\ Patients}

This retrospective study included a total of 23 consecutive patients with malignant tumors of the proximal femur who underwent tumor-wide resection and FAPC reconstruction between 2003 and 2015 at Kanazawa University Hospital. The follow-up period for each patient was $>6$ months. Four patients were excluded from this study: 1 patient with incomplete data; 1 patient underwent a freezing operation of the total femur; and 2 patients with follow-up period was $<6$ months. Eventually, 19 patients ( 10 women, 9 men) were included in this study (Table 1). The mean patient age was 46 years (range, 9-77 years), while the mean follow-up period was 69 months (range, 9-179 months). Pathological diagnoses included osteosarcoma in 8 patients, chondrosarcoma in 3 patients, undifferentiated pleomorphic sarcoma in 1 patient, and metastatic tumor in 7 patients (breast cancer in 3 , lung cancer in 1, renal cell carcinoma in 2, and hepatocellular carcinoma in 1). Newadjuvant and adjuvant chemotherapy were administrated to12 patients. This retrospective study was approved by the ethics committee of Kanazawa University.

\section{Surgical procedure and postoperative management}

Basically, according to the radiological examination, patients with osteoblastic tumor or destruction of less than $1 / 3$ of the cortical bone were given the frozen autograft only treatment for reconstruction. In case with large destruction of cortical bone, bone cement or bone graft were augmented in the bone defect. The lateral approach with curettage of the tumor was used in all patients and biopsy tracts were widely excised with the surgical margin. Any extraskeletal masses surrounding the lesions are resected to obtain adequate surgical margin. Following joint dislocation, the gluteus medius were peeled from greater trochanter, and maintain the continuity of the tensor fascia lata. Afterwards, all the muscles and tendons were detached from proximal femur until the proximal femur can be completely rotated and immersed in liquid nitrogen. To prevent frozen graft fracture, bone marrow and tumor were removed from medullary cavity. The surrounding normal soft tissues are protected by surgical sheets before immersing the proximal femur immersed into the liquid nitrogen. Then, additional $2 \mathrm{~cm}$ bone away from the margin of bony lesion was insert in liquid nitrogen by the pedicle freezing method for $20 \mathrm{~min}$, thawing at room temperature for $15 \mathrm{~min}$ and in distilled water for $15 \mathrm{~min}$. A tourniquet was used to prevent bleeding and tumor dissemination during the pedicle freezing [9] (Fig. 1). An intertrochanteric osteotomy was performed, and the greater trochanter was preserved. The bipolar hemiarthroplasty, cements (antibiotic and anti-tumor drugs were included), long-stemmed prosthesis (span the frozen area) were used in reconstruction (Fig. 2). Finally, the gluteus medius muscles was re-attached to their original anatomical sites using braided polyblend polyethylene suture (bone to tendon). Postoperatively, functional exercise (isometric exercise) was performed immediately from day 1 . Full weight-bearing was permitted at 6 weeks post operation.

\section{Outcome measurement}

All patients underwent clinical and radiological examinations at follow-up. Prosthetic failure was defined as removal of the original prosthesis for any cause. Bone absorption was defined as a lucent shadow around the autograft bone by radiological examination. The followup period was every 6 weeks to 3 months in years $1-2$ after surgery, every 6 months in years $2-5$ years, and every 6-12 months thereafter. Routine examinations included anteroposterior and lateral radiography, chest $\mathrm{CT}$, and a bone scan or MRI as necessary.

\section{Statistical analyses}

Patients functional outcome was evaluated using the MSTS functional score. The survival analysis was performed using the Kaplan-Meier method. The analyses were performed using SPSS ver. 24.0(IBM $\left.{ }^{\circ}\right)$.

\section{Results}

The average prosthetic length of the femoral component was $224 \mathrm{~mm}$ (range, $100-335 \mathrm{~mm}$ ), while mean length of freezing area was $138 \mathrm{~mm}$ (range, $50-270 \mathrm{~mm}$ ). The overall survival rate was $68.4 \%$, and the disease -free survival rates were 50 and $50 \%$ at 5 and 10 years 
Table 1 Date and outcomes of patients treated by frozen autograft-pedicle composite in the proximal femur

\begin{tabular}{|c|c|c|c|c|c|c|c|c|c|c|c|}
\hline Case & Diagnosis & $\begin{array}{l}\text { Enneking } \\
\text { stage }\end{array}$ & $\begin{array}{l}\text { Head } \\
\text { articulation }\end{array}$ & Cement & CTX & $\begin{array}{l}\text { Insert LN } \\
\text { length (mm) }\end{array}$ & $\begin{array}{l}\text { Stem } \\
\text { length in } \\
\text { femur (mm) }\end{array}$ & $\begin{array}{l}\text { MSTS } \\
\text { Score }\end{array}$ & $\begin{array}{l}\text { Follow-up } \\
\text { (mon) }\end{array}$ & $\begin{array}{l}\text { Oncological } \\
\text { outcome }\end{array}$ & $\begin{array}{l}\text { Complication/ } \\
\text { Treatment (mon) }\end{array}$ \\
\hline 1 & Chondrosarcoma & $\mathrm{lb}$ & Bipolar & Yes & No & 160 & 230 & 20 & 99 & NED & \\
\hline 2 & Chondrosarcoma & Ib & Bipolar & Yes & No & 270 & 335 & 30 & 144 & CDF & $\begin{array}{l}\text { Infection with } \\
\text { acetabulum/ } \\
\text { acetabulum revision } \\
(111 \mathrm{~m})\end{array}$ \\
\hline 3 & Chondrosarcoma & $\mathrm{lb}$ & Bipolar & Yes & No & 130 & 290 & 27 & 149 & CDF & \\
\hline 4 & Osteosarcoma & III & Bipolar & Yes & Yes & 90 & 180 & 30 & 84 & NED & \\
\hline 5 & Osteosarcoma & $\| \mathrm{b}$ & Bipolar & Yes & Yes & 190 & 290 & 30 & 120 & CDF & $\begin{array}{l}\text { Dislocation/closed } \\
\text { reductions }\end{array}$ \\
\hline 6 & Osteosarcoma & $\| \mathrm{b}$ & Bipolar & Yes & Yes & 150 & 280 & 28 & 24 & DOOD & $\begin{array}{l}\text { Died of colon } \\
\text { cancer( } 24 \mathrm{~m})\end{array}$ \\
\hline 7 & Osteosarcoma & III & Bipolar & Yes & Yes & 50 & 100 & 20 & 44 & DOD & \\
\hline 8 & Osteosarcoma & III & Bipolar & Yes & Yes & 90 & 145 & 30 & 22 & DOD & \\
\hline 9 & Osteosarcoma & Ila & Bipolar & Yes & Yes & 100 & 140 & 26 & 179 & NED & $\begin{array}{l}\text { Soft tissue recurrence } \\
(107 \mathrm{~m}) \text {, wear of the } \\
\text { acetabulum }(97 \mathrm{~m}) / \mathrm{hip} \\
\text { disarticulation }(107 \mathrm{~m})\end{array}$ \\
\hline 10 & Osteosarcoma & III & Bipolar & Yes & Yes & 250 & 290 & 23 & 9 & DOD & \\
\hline 11 & Osteosarcoma & $\| \mathrm{b}$ & Bipolar & Yes & Yes & 100 & 145 & 24 & 9 & DOD & \\
\hline 12 & UPS & Ila & Bipolar & Yes & No & 150 & 210 & 19 & 66 & CDF & \\
\hline 13 & Breast cancer & N/A & Bipolar & Yes & No & 110 & 220 & 28 & 57 & AWD & \\
\hline 14 & Breast cancer & N/A & Bipolar & Yes & No & 100 & 205 & 27 & 150 & CDF & $\begin{array}{l}\text { Fracture }(12 \mathrm{~m}), \\
\text { prothesis fracture } \\
(112 \mathrm{~m}), \text { wear of the } \\
\text { acetabulum }(106 \mathrm{~m}) / \\
\text { megaprosthesis } \\
\text { conversion }(112 \mathrm{~m})\end{array}$ \\
\hline 15 & Breast cancer & N/A & Bipolar & Yes & Yes & 130 & 180 & 25 & 9 & AWD & \\
\hline 16 & Lung CA & N/A & Bipolar & Yes & Yes & 150 & 280 & 30 & 36 & NED & \\
\hline 17 & $\mathrm{RCC}$ & N/A & Bipolar & Yes & No & 100 & 240 & 30 & 61 & CDF & \\
\hline 18 & $\mathrm{RCC}$ & N/A & Bipolar & Yes & Yes & 110 & 240 & 28 & 33 & DOD & \\
\hline \multirow[t]{2}{*}{19} & $\mathrm{HCC}$ & N/A & Bipolar & Yes & Yes & 200 & 250 & 26 & 12 & AWD & $\begin{array}{l}\text { Infection with } \\
\text { acetabulum (3 m) }\end{array}$ \\
\hline & & & & & & 138 & 224 & 26.4 & 68.8 & & \\
\hline
\end{tabular}

$F$ female, $M$ male, UPS undifferentiated pleomorphic sarcoma, $C A$ cancer, $R C C$ renal cell carcinoma, $H C C$ hepatocellular carcinoma, $A W D$ alive with disease, $C D F$ continuous disease free, $D O D$ dead of disease, DOOD dead of other disease, NED no evidence of disease, CTX chemotherapy, OP operation, MSTS Musculoskeletal Tumor Society

respectively (Fig. 3a, b). Five-year and 10-year recurrence rates were 100 and $80 \%$, respectively (Fig. 3c). At the last follow-up, 6 of 19 patients were continuous disease free, 3 were alive with disease, 4 had no evidence of disease after treatment for metastasis or recurrence, and $2 \mathrm{pa}-$ tients had lung metastasis for which they underwent thoracoscopic excision. 1 patient had bone metastasis of lung cancer that was treated by wide resection. One other patient had local recurrence of disease from residual soft tissue around the femur and underwent reresection. Five patients died of the disease. The mean MSTS functional score of the patients was 26.4 points (rang, 19-30 points).
Among the 4 patients with the follow-up period > 10 years, the FAPC survival rates were 100 and 50\% at 5 and 10 years respectively (Fig. 3d). Five of the 19 (26\%) patients had complications, including 1 who developed a fracture at 12 months post operation, which had been controlled by conservative treatment. At 112 months post operation, the prosthesis broke, and the patient was subjected to conversion to megaprosthesis. Another patient developed local recurrence of the disease from residual soft tissue around the proximal femur for which hip disarticulation was performed at 107 months post operation (Table 1). 

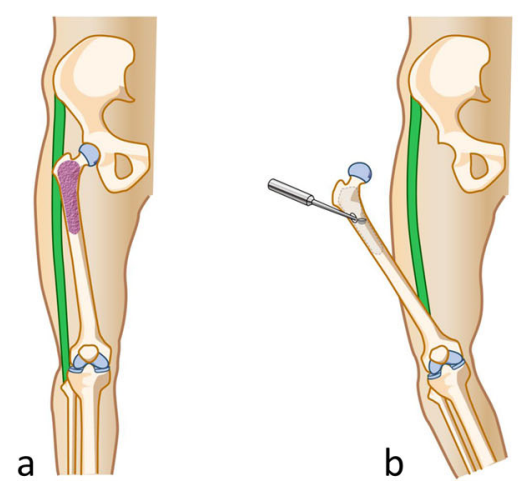

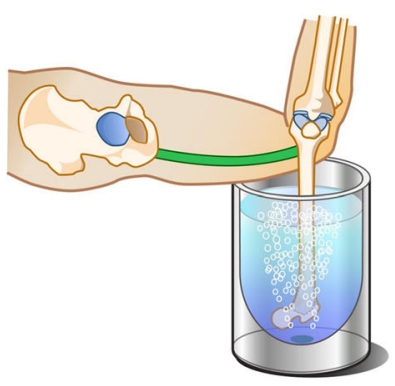

C

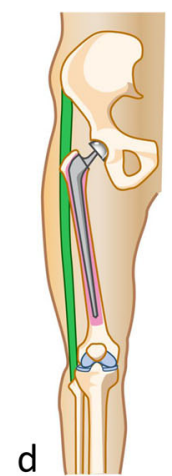

Fig. 1 Frozen autograft-prothesis composite used for femoral reconstruction. a Tumor in the proximal femur. b Curettage of the tumor after joint dislocation. $\mathbf{c}$ Pedicle freezing in liquid nitrogen. $\mathbf{d}$ ligament and FAPC reconstruction

Two cases of deep infection around the acetabulum were managed with debridement, antibiotic bone cement implantation, and acetabular component revision. Wear of the acetabulum occurred in 2 cases, both of which were treated by conversion to an acetabular component at 97 and 106 months postoperatively. One patient had a dislocation that was managed by using closed reductions. At the last follow-up, no patients had greater trochanter avulsion, obvious absorption around the frozen bone, prosthetic loosening, or leg length discrepancy.

\section{Discussion}

With the collaboration of multidisciplinary team, the life expectancy has been increased significantly in patients suffer from malignant tumor. Therefore, to improve the quality of life of patients, various reconstruction methods after bone tumors excision have been developed, including megaprosthesis, allografting, and tumor-bearing bone grafts (irradiated bone, pasteurized bone, and frozen bone). Given that biological reconstructions can achieve acceptable long-term functional outcome, biological reconstructions have received increasing attention [10].

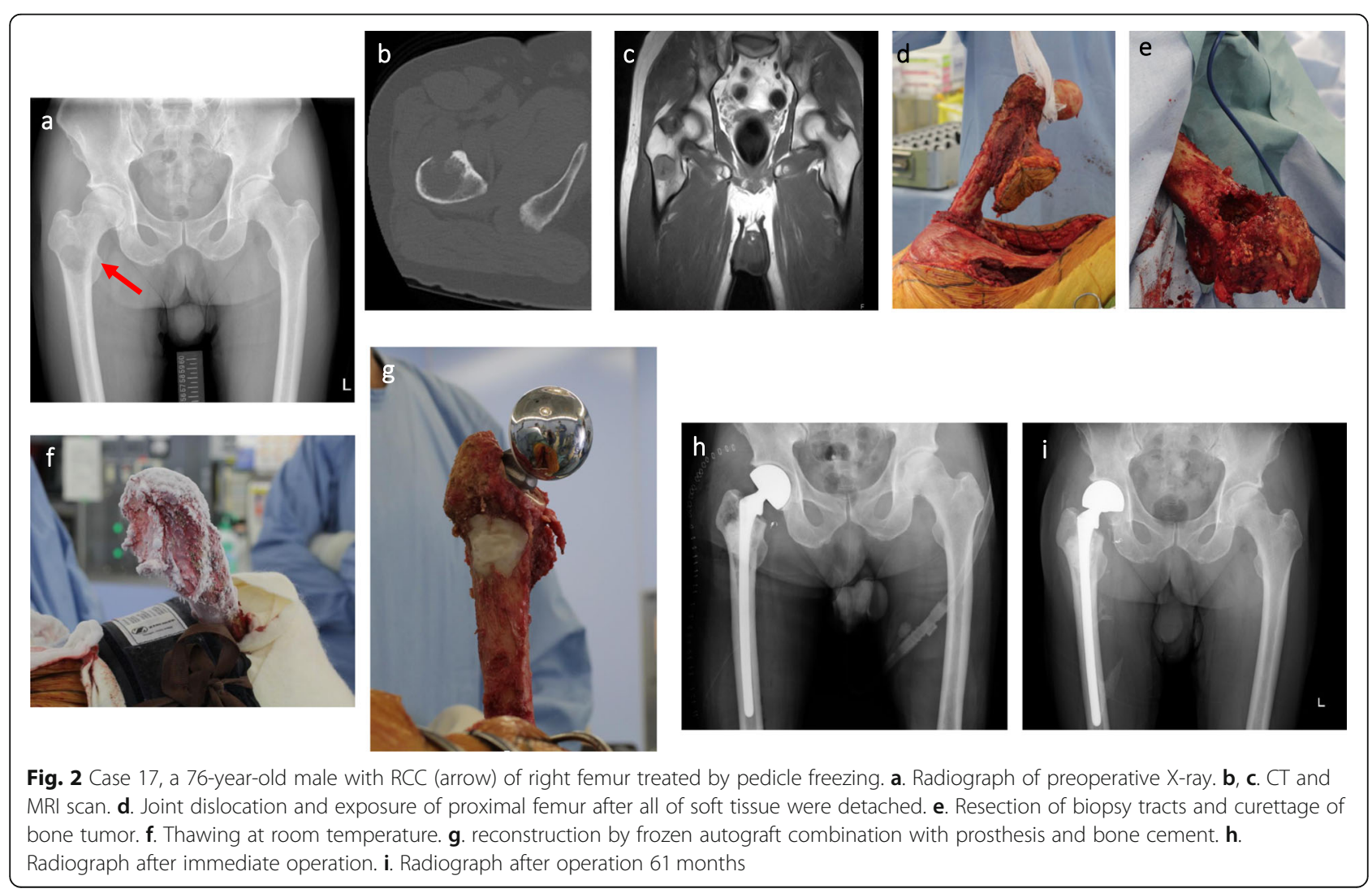




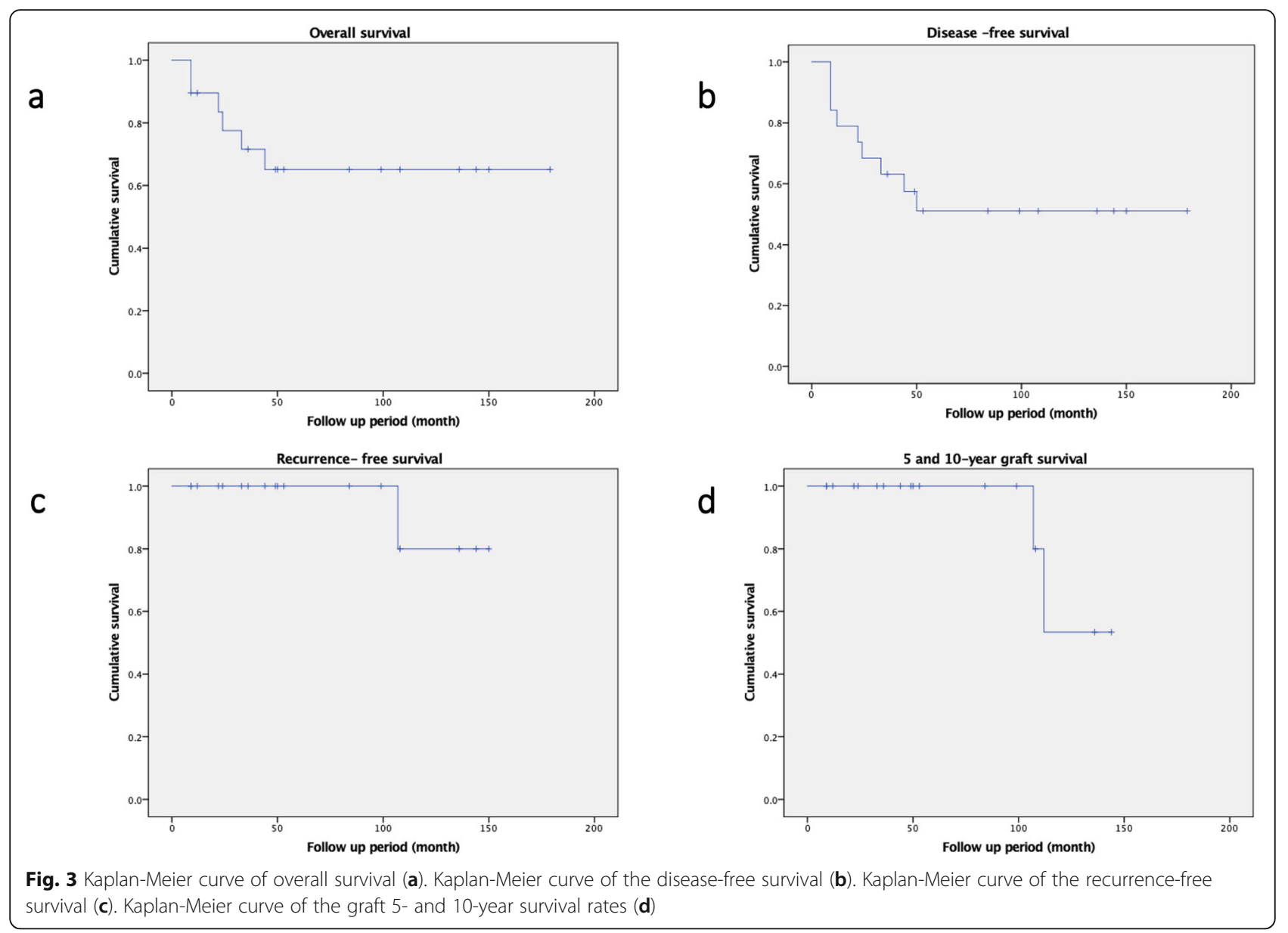

Tumor-bearing bone graft is one of the biological reconstructions. In the past 20 years, tumor-bearing autografts frozen with liquid nitrogen have been reported as safe and effective methods for treating osteoblast tumors of various types and locations in basic experimental studies and clinical practices $[8,11-15]$. The beneficial effects include a shorter union period, restoration of bone stock, lower cost, osteoinduction, osteoconduction, perfect fit, ease of soft-tissue attachment, activation of antitumor immune response and decreased disease transmission $[8,12]$. In fact, FAPC by pedicle method shows significant advantage in proximal femoral tumors. First, it does not require femoral osteotomy or wait for the junction healing. Second, it is easy to reattach the ligaments and soft tissue around the proximal femur to the original anatomic site to increased hip joint stability. Third, it can potentially preserve maximal bone matrix to avoid further retreatment resulting from insufficient bone mass. In theory, all biological reconstructions have similar advantages and disadvantage. However, due to the loss of osteoinductive and osteogenic properties after thermal or radiation treatment, the allograft might have potential risk factors which require further surgery, such as nonunion with the host bone, graft fracture, bone resorption and immunological reactions [5-7]. Takata et al. also reported that tumor-bearing frozen bones maintains their microstructure and osteoinductive ability compared to pasteurization, autoclaving and allograft [11].

Biomechanical stability is of great concern to biological reconstructions. Lee et al. reported that the pasteurization decreases the biologic and mechanical properties and reduces strength to less than that of an allograft [16]. Interestingly, Yamamoto et al. had reported that the frozen bone has sufficient biomechanical strength for limb reconstruction that is comparable to pasteurized autografts and allografts [13].

Previous studies reported that an APC reconstruction exhibited satisfactory 5-year survival rate $(72-90 \%)$ and MSTS score (77-90\%), respectively. APC is a better reconstruction option if easily available. Remarkably, graft-host junction union is a major problem, and the nonunion rate is reportedly $5-19 \%[5,6,17-19]$. On the other hand, Eid et al. [20] reported the outcomes of the application of the pasteurized APC in 18 patients; MSTS functional score was $80 \%, 5$ - and 10-year graft survival 
rates of $86 \%$, respectively; mean graft-host junction union time of 13 months, and 1 case of non-union. Another study using extracorporeal irradiated APC by Chen et al. [21] reported an MSTS score of $72 \%$, mean graft-host junction union time of 20 months, and 5-year graft survival rate of $85 \%$. It seems that all biological reconstruction methods feature acceptable functional outcomes and implant survival rates. A few cases of nonunion or delayed union have been reported, although many studies reported that using the step-cut osteotomy, autogenous or allogenous bone graft into host bone, and non-cemented prostheses increased graft-host junction healing and stability in all biological reconstructions [5, 19, 22] (Table 2).

Greater trochanter stability in biological reconstruction is also a concern. Instability of abductors reconstruction prone to potentially severe complications, such as greater hip abductors avulsion, resorption, hip abductor avulsion, Trendelenburg gait or dislocation, which lead to poor function and a protracted postoperative rehabilitation period $[19,20]$. Although abductors reconstruction methods are controversial, the hip abductor strength and gait which APC seems to be superior to megaprothesis $[5,19,23]$. A few studies emphasize the importance of preserving the proximal capsule and re-sutured onto the allograft to prevent hip dislocations [17]. In the current study, similar procedures were also applied to peeled gluteus medius from greater trochanter and reattached the gluteus medius to the original site. Bone to tendon reconstruction which might easy to restore abduction strength due to integrity of the gluteus medius. In this study, only one patient occurred joint dislocation, which is comparable to other methods of biological reconstruction [7, 23, 24].

In addition, bone cement or graft plus long-stemprosthesis has been used in some patients with metastases combined lytic to make up for osteolytic destruction in the proximal femur. Such treatment will provide sufficient mechanical strength and stabilization of bones. Given that pedicle freezing required more a longer incision and muscle dissection, the authors encouraged isometric exercise to avoid complication in early postoperative period. The bone cement and prosthesis provide rigid fixation and avoid bone union which make it possible for full weight-bearing at 6 weeks post operation. Meanwhile, all the patients underwent physical exercise to learn prevention hip dislocation, and postoperative bracing provided sufficient support to minimize dislocations if necessary. In case of large resection of muscles, the mesh can be used to attach surrounding soft tissues, and abduction brace is used to prevent hip dislocation. Of note, if patients showed signs of severe destruction of cortex $(>2 / 3)$ in the proximal femur, megaprosthesis was recommended [12].
Megaprosthesis has satisfactory short- to mediumterm outcome, early mobilization and weight-bearing, and short operative time; however, abductor muscles reattachment remains an issue need to be concerned. Accumulating evidence indicates using an artificial ligament to affix the megaprosthesis can promote softtissue reconstruction and achieve better joint stability and functional outcomes [25]. In fact, artificial ligament use is probably unable to reduce the occurrence of prosthetic complications such as aseptic loosening, prosthesis breakage, infection, and stress shielding [26]. Moreover, long-term prosthetic failure rate is between 6 and 33\%, mean MSTS score is between 63 and 83\%, and the major complications were infection $(5-13 \%)$ and dislocation $(0-20 \%)[4,18,26-28]$ (Table 2). The application of silver- or iodine- coated implants had been reported to reduce overall infection rates $[29,30]$. However, a higher cost burden, unavailability in some countries and the limited bone mass complicate revision surgeries.

The various reconstructive alternatives have acceptable oncological and functional outcomes. However, each method has its own limitations, and thus it is crucial for choose the proper method to maximize the benefits for each patient. Surgeons must carefully consider the patient's age, general condition, response to chemotherapy, and expectations when individualizing a treatment plan.

In the current study, the functional outcome was similar to those of other reconstruction methods. The mean MSTS functional score was $88 \%$, and the 5- and 10-year graft survival rates were 100 and $50 \%$, respectively. At the last follow-up, no prosthesis loosening or obvious lucent shadows around the autograft bone was observed on radiological examination. Only 1 patient had local recurrence around the residual soft tissue for which hip disarticulation was performed after 2 re-excisions. Wear of the acetabulum occurred in 2 patients despite the use of bipolar hemiarthroplasty, but this might be an inevitable long-term complication of joint replacement.

This study had several limitations. First, due to its retrospective design and single center, a relatively small number of patients were enrolled, a follow-up $>10$ years was available for only 4 of the 19 patients. Second, no control group was available for comparison of functional outcomes; thus, our results could be compared to only those of prior studies. Similarly, the accuracy of our results was lower than those of randomized study. Third, the patients had various diagnoses and were treated with various chemotherapy regimens, which might affect survival rates and functional outcomes. Therefore, to assess the efficacy and safety of this procedure, a prospective study which compares the functional outcomes and survival rates of several reconstruction methods over a long-term follow-up period needs to be performed in the future. 
Xu et al. BMC Musculoskeletal Disorders $\quad$ (2020) 21:81

Page 7 of 8

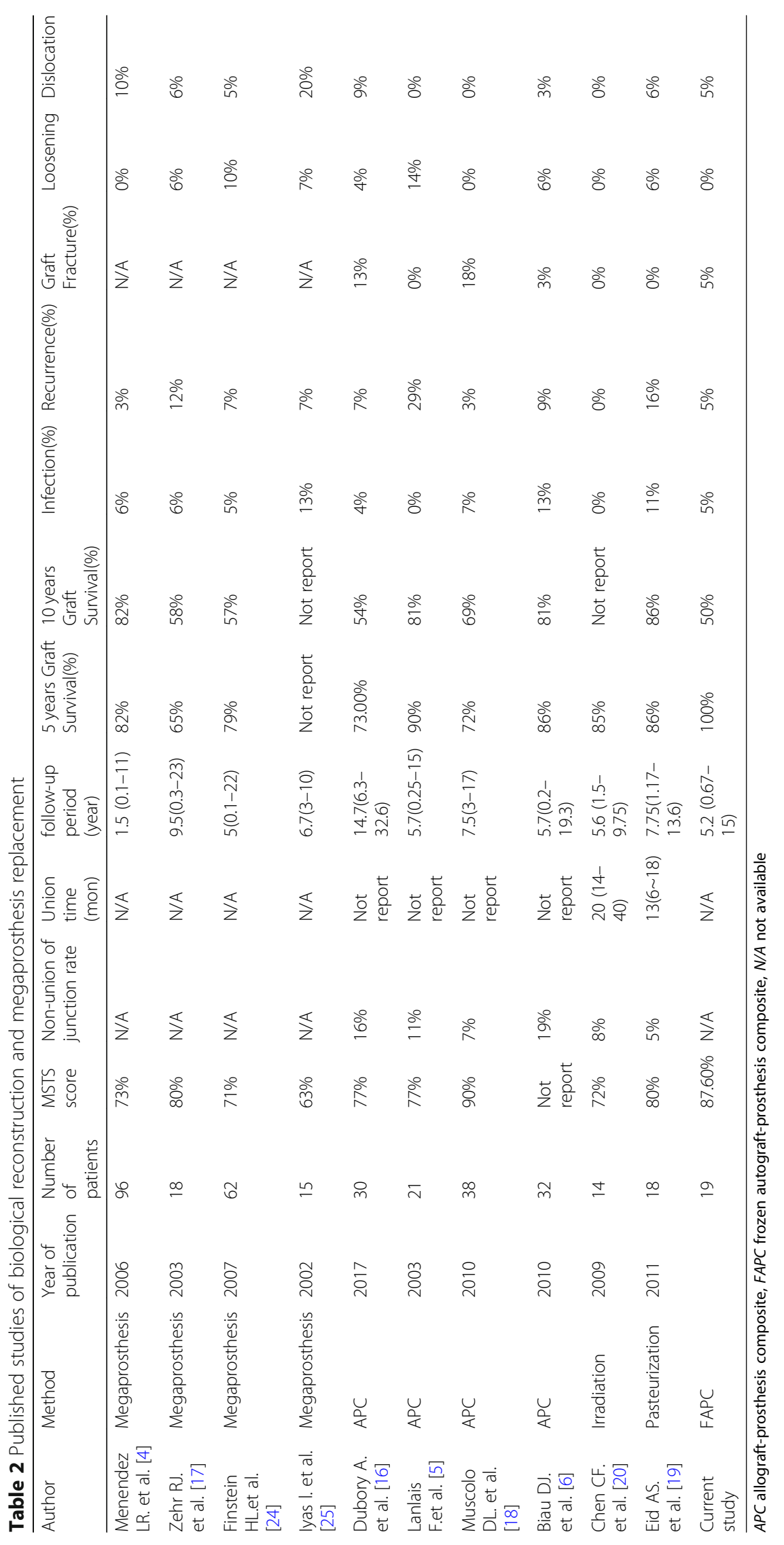




\section{Conclusions}

Our findings suggest that FAPC reconstruction is a good method of treating patients with malignant bone tumor in the proximal femur. With no femoral osteotomy, FAPC reconstruction can achieve a better clinical outcome and reduce complications, which is comparable to other methods of biological reconstruction or megaprosthesis.

\section{Abbreviations}

APC: Allograft-prosthesis composite; FAPC: Frozen autograft-prosthesis composite; MSTS: Musculoskeletal Tumor Society

\section{Acknowledgements}

Not applicable.

\section{Authors' contributions}

GX performed the study design, analysis of date and manuscript drafting. SM1 collected the data and revised the manuscript. NY, KH, AT, KI, TH, YT HA, $\mathrm{HY}, \mathrm{SM} 2$ and HT analysis the data. All authors approved the final manuscript.

\section{Funding}

This study was not funded by any foundation, association or agency.

\section{Availability of data and materials}

The datasets will be available from the corresponding author if need to obtain the data and materials.

\section{Ethics approval and consent to participate}

The study was approved by the ethics committee of Kanazawa University, and written informed consent was obtained from all patients before surgical treatment.

\section{Consent for publication}

Not applicable.

\section{Competing interests}

The author declare that they have no conflict of interest.

Received: 2 October 2019 Accepted: 3 February 2020

Published online: 06 February 2020

\section{References}

1. Groundland JS, Ambler SB, Houskamp LD, Orriola JJ, Binitie OT, Letson GD. Surgical and functional outcomes after limb-preservation surgery for tumor in pediatric patients: a systematic review. JBJS Rev. 2016:4-2.

2. Veth $R$, van Hoesel R, Pruszczynski M, Hoogenhout J, Schreuder B, Wobbes T. Limb salvage in musculoskeletal oncology. Lancet Oncol. 2003;4:343-50.

3. Aksnes LH, Bauer HC, Jebsen NL, Folleras G, Allert C, Haugen GS, Hall KS. Limb-sparing surgery preserves more function than amputation: a Scandinavian sarcoma group study of 118 patients. J Bone Joint Surg (Br). 2008;90:786-94.

4. Menendez LR, Ahlmann ER, Kermani C, Gotha H. Endoprosthetic reconstruction for neoplasms of the proximal femur. Clin Orthop Relat Res. 2006:450:46-51.

5. Langlais F, Lambotte JC, Collin P, Thomazeau H. Long-term results of allograft composite total hip prostheses for tumors. Clin Orthop Relat Res. 2003:414:197-211.

6. Biau DJ, Larousserie F, Thevenin F, Piperno-Neumann S, Anract P. Results of 32 allograft-prosthesis composite reconstructions of the proximal femur. Clin Orthop Relat Res. 2010;468:834-45.

7. Donati D, Giacomini S, Gozzi E, Mercuri M. Proximal femur reconstruction by an allograft prosthesis composite. Clin Orthop Relat Res. 2002;394:192-200.

8. Tsuchiya H, Wan SL, Sakayama K, Yamamoto N, Nishida H, Tomita K. Reconstruction using an autograft containing tumour treated by liquid nitrogen. J Bone Joint Surg (Br). 2005;87:218-25.

9. Tsuchiya H, Nishida H, Srisawat P, Shirai T, Hayashi K, Takeuchi A, et al. Pedicle frozen autograft reconstruction in malignant bone tumors. J Orthop Sci. 2010;15:340-9.
10. Gautam D, Malhotra R. Megaprosthesis versus allograft prosthesis composite for massive skeletal defects. J Clin Orthop Trauma. 2018;9:63-80.

11. Takata M, Sugimoto N, Yamamoto N, Shirai T, Hayashi K, Nishida H, et al. Activity of bone morphogenetic protein-7 after treatment at various temperatures: freezing vs. pasteurization vs. allograft. Cryobiology. 2011;63:235-9.

12. Miwa S, Takeuchi A, Shirai T, Yamamoto N, Nayashi K, Nishida H, et al. Outcomes and complications of reconstruction using tumor-bearing frozen autografts in patients with metastatic bone tumors. Anticancer Res. 2014;34 5569-77.

13. Yamamoto N, Tsuchiya H, Tomita K. Effects of liquid nitrogen treatment on the proliferation of osteosarcoma and the biomechanical properties of normal bone. J Orthop Sci. 2003;8:374-80.

14. Takeuchi A, Yamamoto N, Hayashi K, Matsubara H, Kimura H, Miwa S, et al. Growth of epiphysis after epiphyseal-preservation surgery for childhood osteosarcoma around the knee joint. BMC Musculoskelet Disord. 2018:19:185.

15. Abe K, Yamamoto N, Hayashi K, Takeuchi A, Miwa S, Igarashi K, et al. The usefulness of wide excision assisted by a computer navigation system and reconstruction using a frozen bone autograft for malignant acetabular bone tumors: a report of two cases. BMC Cancer. 2018;18:1036.

16. Lee SY, Jeon DG, Cho WH, Song WS, Kong CB, Kim BS. Pasteurized autograft-prosthesis composite reconstruction may not be a viable primary procedure for large skeletal defects after resection of sarcoma. Sarcoma. 2017;9710964-9.

17. Dubory A, Mascard E, Dahan M, Anract P, Counrt C, Boisgard S, et al. Longterm functional and radiological outcomes of allograft hip prosthesis composite. A fourteen -year follow-up study. Int Orthop. 2017:41:1337-45.

18. Zehr RJ, Enneking WF, Scarborough MT. Allograft-prosthesis composite versus megaprosthesis in proximal femoral reconstruction. Clin Orthop Relat Res. 1996;322:207-23.

19. Muscolo DL, Farfalli GL, Aponte-Tinao LA, Ayerza MA. Proximal femur allograft-prosthesis with compression plates and a short stem. Clin Orthop Relat Res. 2010;468:224-30

20. Eid AS, Jeon DG, Song WS, Lee SY, Cho WH. Pasteurized autograftprosthesis composite for proximal femoral reconstruction: an alternative to allograft composite. Arch Orthop Trauma Surg. 2011;131:729-37.

21. Chen CF, Chen WM, Cheng YC, Chiang CC, Huang CK, Chen TH. Extracorporeally irradiated autograft-prosthetic composite arthroplasty using AML extensively porous-coated stem for proximal femur reconstruction: a clinical analysis of 14 patients. J Surg Oncol. 2008;100:418-22.

22. Malhotra R, Kiran Kumar GN, Digge VK, Kumar V. The clinical and radiological evaluation of the use of an allograft-prosthesis composite in the treatment of proximal femoral giant cell tumours. Bone Joint J. 2014;96-B:1106-10.

23. Farid $Y$, Lin PP, Lewis VO, Yasko AW. Endoprosthetic and allograft-prosthetic composite reconstruction of the proximal femur for bone neoplasms. Clin Orthop Relat Res. 2006;442:223-9.

24. Benedetti MG, Bonatti E, Malfitano C, Donati. Comparison of allograftprosthetic composite reconstruction and modular prosthetic replacement in proximal femur bone tumors: functional assessment by gait analysis in 20 patients. Acta Orthop. 2013;84:218-23.

25. Du Z, Tang S, Yang R, Tang $X$, Ji T, Guo W. Use of an artificial ligament decreases hip dislocation and improves limb function after Total femoral prosthetic replacement following femoral tumor resection. J Arthroplast. 2018:33:1507-14.

26. Clarke HD, Berry DJ, Sim FH. Salvage of failed femoral megaprostheses with allograft prosthesis composites. Clin Orthop Relat Res. 1998:356:222-9.

27. Finstein JL, King JJ, Fox EJ, Ogilvie CM, Lackman RD. Bipolar proximal femoral replacement prostheses for musculoskeletal neoplasms. Clin Orthop Relat Res. 2007;459:66-75.

28. Ilyas I, Pant R, Kurar A, Moreau PG, Younge DA. Modular megaprosthesis for proximal femoral tumors. Int Orthop. 2002;26:170-3.

29. Shirai T, Tsuchiya $H$, Nishida H, Yamamoto N, Watanabe K, Nakase J, et al. Antimicrobial megaprostheses supported with iodine. J Biomater Appl. 2014:29:617-23.

30. Hardes J, von Eiff C, Streibuerger A, Balke M, Budny T, Henrichs MP, Hauschild $\mathrm{G}$, Ahrens $\mathrm{H}$. Reduction of periprosthetic infection with silvercoated megaprostheses in patients with bone sarcoma. J Surg Oncol. 2010; 101:389-95

\section{Publisher's Note}

Springer Nature remains neutral with regard to jurisdictional claims in published maps and institutional affiliations. 